\title{
Thermodynamic analysis of an ecologically restored plant community:Process and diversity
}

\author{
Xinxi $\mathrm{Fu}^{1}$, Zijian $\mathrm{Wu}^{2}$, Mingli Chen ${ }^{1}$, Linnan Ouyang ${ }^{3}$, and Xiaofu $\mathrm{Wu}^{4}$ \\ ${ }^{1}$ Central South University of Forestry and Technology \\ ${ }^{2}$ Hunan Academy of Forestry Science \\ ${ }^{3}$ China Eucalypt Research Centre, State Forestry and Grassland Administration \\ ${ }^{4}$ Affiliation not available
}

May 18, 2020

\begin{abstract}
The experimental data used for testing the applicability of the thermodynamic equations presented in the theoretical section were obtained from an ecological restoration project implemented at a manganese tailing site. Restoration of the plant community was shown to be an irreversible process characterized by spontaneous increases in its total biomass CT and total number of plant species $\mathrm{N}$ associated with increases in its enthalpy H, Gibbs free energy G and entropy S. Species enrichment was the cause for the decease in mass ratio xi (biomass of a species Ci divided by CT) and biomass growth potential $\mu \mathrm{i}$ (the partial derivative of $\mathrm{Gi}$ with respect to $\mathrm{Ci}$ ). The increase in $\mathrm{s} / \mathrm{CT}$ (s denoting the ratio of $\mathrm{S}$ to gas constant $\mathrm{R}$ ) associated with decrease in $\mathrm{f} / \mathrm{CT}$ (f denoting the ratio of $\mathrm{G}$ to $\mathrm{RT}$ ) with increasing $\mathrm{N}$ confirmed that the restored plant community possessed natural trends towards increase in its species richness and evenness. The observed trends gave support to use of the thermodynamic functions for describing the productivity-biodiversity relationship. The present analysis did not fully prove the use of the Shannon form of information entropy as a biodiversity index for the investigated plant communities. Because of the presence of significant differences in individuals among species, the biodiversity of the plant community could not be uniquely determined by its individual numbers. In comparison, the entropy factor s was shown to be a suitable biodiversity index. The fact that $\mathrm{N}$ is the key factor that determines the changes in s/CT and f/CT makes ${ }^{N}>0$ ause fulindex fordeterminingthedirectionof spontaneouschangesforallopensystemswithcontinuousinputofmatterandenergy. Asameasureo

Running head: Thermodynamic analysis of a plant community

The title:

Thermodynamic analysis of an ecologically restored plant community:Process and diversity

Xinxi $\mathrm{Fu}^{1}$, Zijian $\mathrm{Wu}^{2}$, Mingli Chen ${ }^{1}$, Linnan Ouyang ${ }^{3}$, Xiaofu $\mathrm{Wu}^{1^{*}}$

1. College of Environmental Science and Engineering, Central South University of Forestry and Technology, Changsha 410004, China.

2. Hunan Academy of Forestry Science, Changsha 410004, China.

3. China Eucalypt Research Centre, State Forestry and Grassland Administration, Zhanjiang 524000, China.

*: Corresponding author: Tel: 0086.13787219881.wuxiaofu530911@vip.163.com
\end{abstract}

Abstract. The experimental data used for testing the applicability of the thermodynamic equations presented in the theoretical section were obtained from an ecological restoration project implemented at a 
manganese tailing site. Restoration of the plant community was shown to be an irreversible process characterized by spontaneous increases in its total biomass $C_{\mathrm{T}}$ and total number of plant species $N$ associated with increases in its enthalpy $H$, Gibbs free energy $G$ and entropy $S$. Species enrichment was the cause for the decease in mass ratio $x_{\mathrm{i}}$ (biomass of a species $C_{\mathrm{i}}$ divided by $C_{\mathrm{T}}$ ) and biomass growth potential $\mu_{\mathrm{i}}$ (the partial derivative of $G_{\mathrm{i}}$ with respect to $\left.C_{\mathrm{i}}\right)$. The increase in $s / C_{\mathrm{T}}(s$ denoting the ratio of $S$ to gas constant $R$ ) associated with decrease in $f / C$ T $(f$ denoting the ratio of $G$ to $\mathrm{R} T$ ) with increasing $N$ confirmed that the restored plant community possessed natural trends towards increase in its species richness and evenness. The observed trends gave support to use of the thermodynamic functions for describing the productivitybiodiversity relationship. The present analysis did not fully prove the use of the Shannon form of information entropy as a biodiversity index for the investigated plant communities. Because of the presence of significant differences in individuals among species, the biodiversity of the plant community could not be uniquely determined by its individual numbers. In comparison, the entropy factor $s$ was shown to be a suitable biodiversity index. The fact that $N$ is the key factor that determines the changes in $s / C_{\mathrm{T}}$ and $f / C_{\mathrm{T}}$ makes ${ }^{N}>0$ ause fulindex fordeterminingthedirectionof spontaneouschanges forallopensystemswithcontinuousinputofmatterana

Key words: ecological restoration; metal contamination; thermodynamic functions; spontaneous changes; biodiversity.

\section{Introduction}

The objective of this study is to examine the applicability of the thermodynamic equations presented in the theoretical section (Theoretical basis) for description of a plant community ecologically restored at a manganese tailing site. Remediation of a damaged ecosystem should be a manipulated process welldesigned with proper measures and explicit targets (Baldera et al., 2018; Laughlin, 2014; Zhao et al., 2016; Haapalehto et al., 2017; Tongkoom et al., 2018) that can maximize the benefits and minimize the damages that are currently existed and that can possibly be brought into the site due to use of improper methods (González et al., 2014; Wallace et al., 2017; Garrouj et al., 2019). Performing a thermodynamic analysis focusing on changes in individual, population and community traits in the restoration process can provide useful information not only for assessment of the remediation effect but also for development of relevant knowledge and technology (Hesse et al., 2018; Kollmann \& Mahy, 2018; Fiedler et al., 2018).

Biomass quantity $C$, individual number $m$ and species number $N$ are the three basic parameters that can be directly used as indicators for, respectively, productivity, species abundance and species richness. Other parameters developed for describing a specific state of an ecosystem, such as the Shannon-Wiener and Simpson indexes (Ricklefs \& Relyea, 2014), exergy (Jørgensen, 2010; Jørgensen et al., 2016) and entropybased indicators (Laner et al., 2017; Ludovisi \& Scharler, 2017), etc., are all presented as functions of $C$ , $m$ or $N$, or a combination of them. Accounted for by their additive nature, $C, m$ and $N$ are extensive properties of an ecosystem. Thus, as primary state variables of an ecosystem, $C, m$ and $N$ all have fixed values at a given state and their changes can be uniquely determined by their difference between states regardless of the process history. It follows that all indexes presented as functions of either $C, m$ or $N$ are also state variables with defined meanings in thermodynamics. The conventional indexes are useful and sufficient if one is only interested in assessing the remediation effect. They are not, however, sufficient enough if one is also interested in revealing their related mechanisms and apprehending their significances in ecology. The difference, for an example, in mathematical expressions between the Shannon-Wiener index (or the Shannon form of information entropy) as a function of $m$ and $N$ (Harte \& Newman, 2014; Newman et al., 2014) and entropy $S$ as a function of $C$ and $N$ will lead to differences in advantages and disadvantages of their applications. Analysis of their difference using the obtained experimental data can offer a better understanding of the restoration process reflected by the changes in $C, m$ and $N$.

Two fast-growing tree species $P$. fortunei and $K$. bipinnata were used as dominant species in the implemented restoration project. Analysis of their thermodynamic behaviors and the changes in their contribution rates with increase in species richness and abundance should be a meaningful approach to determine the causes that lead to the changes in the internal energy state of the restored plant community. Due to limited scope, the present analysis will be focused on identification of the key thermodynamic factors related to spontaneous 
changes and biodiversity of the restored plant community.

\section{Methods}

Applied remediation measures

Screening of metal-tolerant species known as hyper-accumulators applied for remediation of a metal contaminated site has been a worldwide hotspot of research (García et al., 2009; Tie et al., 2005; Zhang et al., 2015). A hyper-accumulator does not only tolerate high concentrations of a metal element in its tissue but also possesses high under-ground to above-ground metal transfer rates (Abreu et al., 2102; Adamo et al.. 2014). The demerits for use of most of the reported hyper-accumulators, however, are their low levels of biomass growth associated thus with low levels of total metal uptake. In addition, the nature of their tolerance to a specific metal element also limits their application on multiple metal contaminated sites. Attentions in related fields have been paid to use of tree species ( Bidwell et al., 2002; Yang et al., 2008; Wang et al., 2010) . As most of the fast-growing tree species cannot survive under heavily metal contaminated conditions, the commonly applied methods for forestation at a metal tailing site are either to seal its upper layer with an uncontaminated soil (Gomez-Ros et al., 2013) or to use an immobilization reagent to reduce its upper layer's metal toxicity (Vargas-García et al., 2012, Yang et al., 2017). The disadvantages of soil sealing and metal immobilization are mainly their high costs.

The experimental site under study was a manganese tailing wasteland located at Xiangtan, Hunan, China. The site was poor in nitrogen and phosphorus but very high in contents of manganese, lead, zinc, copper, cadmium and chromium. The applied remediation strategy was a combination of the above mentioned methods using tree species, metal-tolerant species and remediation reagent. Two fast-growing tree species (Paulownia fortunei and Koelreuteria bipinnata) screened from the native species naturally distributed in the uncontaminated region nearby the tailing site were used as dominant phyto-remediation species. Before transplanting their seedlings, a bacteri-rich organic manure specifically prepared for the tailing site was amended to their rhizospheric areas. The enrichment of the site's biodiversity was counted on natural germination of the native metal tolerant plant species based on the soil seed bank theory (Tang et al., 2006). To prevent the spread of metal contamination to surrounding areas, an ecological interception belt along the border of the tailing site was established and its outlet was connected to a constructed wetland system for treatment of runoff.

Detailed experimental information has been presented in previous work (Ouyang et al., 2016; Wu et al., 2017). The experiment plots, sample analysis and equations for calculation are briefly described below.

Experimental plot

The total experimental area was 4.4 hectares consisting of the three plots:

(I): $4.0 \mathrm{hm}^{2}$, manganese tailing site amended with an organic manure as a base fertilizer to increase the nutrient availability and reduce the metal toxicity in the rhizosphere before transplanting one-year old seedlings of $P$. fortunei and $K$. bipinnata (spacing 2-2.5m, 1000 plants of each species $/ \mathrm{hm}^{2}$ ).

(II): $0.2 \mathrm{hm}^{2}$, manganese tailing site amended with equivalent amounts of chemical fertilizers in the rhizosphere before transplanting one-year old seedlings of the same tree species (spacing 2-2.5m, 1000 plants of each species $/ \mathrm{hm}^{2}$ ) and

(III): $0.2 \mathrm{hm}^{2}$, uncontaminated site in the vicinity of the tailing wasteland, a plant community naturally developed under normal soil conditions.

Sample collection and analysis

Plant and soil samples were collected from three fixed standard blocks (approximately $667 \mathrm{~m}^{2}$ each) in each plots in June and October each year from 2009 to 2016 and analyzed following standard procedures (GB15618-1995; GB3838-2002; GB18918-2002, People's Republic of China). The numbers of individual plant and plant species were counted on-site. The relative standard deviations in duplicate sample analyses ranged 
between $8.4 \%-16.4 \%$ in biomass measurement and $5.1 \%-18.3 \%$ in metal uptake determination. The average values of the measurements were used for further calculation. The differences in related values between treatment plots were compared with LSD analysis of variance.

Calculation

For comparison, the Shannon-Wiener index (the Shannon form of the information entropy) was calculated by

$S I=[?]\left(m_{\mathrm{i}} / M\right) \ln \left(M / m_{\mathrm{i}}\right)=[?] p_{\mathrm{i}} \ln \left(1 / p_{\mathrm{i}}\right) M=[?] m_{\mathrm{i},} p_{\mathrm{i}}=[?] m_{\mathrm{i}} / M, \mathrm{i}=1,2, \ldots, N(1)$

where $m_{\text {i }}$ denotes the number of individuals of the ith plant species, $M$ denotes the total number of individuals of the plant community, $N$ denotes the total number of species of the plant community and $p$ i stands for the relative abundance of the ith plant species (Eq. 1 referring to Eq. 15 in the theoretical section).

The thermodynamic factors $h, s$ and $f$ (enthalpy $H$, entropy $S$ and Gibbs free energy $G$ divided, respectively, by gas constant $\mathrm{R}$ and temperature $T$ ) were calculated by

$h=H /(\mathrm{RT})=C_{\mathrm{T}} \ln \left(N_{\mathrm{m}}\right)=C_{\mathrm{T}} \ln (66) C_{\mathrm{T}}=[?] C_{\mathrm{i}}(2)$

$s=T S /(\mathrm{R} T)=S / \mathrm{R}=[?] C_{\mathrm{i}} \ln \left(1 / x_{\mathrm{i}}\right) x_{\mathrm{i}}=C_{\mathrm{i}} / C_{\mathrm{T}}, C_{\mathrm{i}}=[?] c_{\mathrm{ij}}, \mathrm{j}=1,2, \ldots, m_{\mathrm{i}}(3)$

$f=G /(\mathrm{R} T)=h-s=C_{\mathrm{T}} \ln (66)-[?] C_{\mathrm{i}} \ln \left(1 / x_{\mathrm{i}}\right)(4)$

$s / C_{\mathrm{T}}=\left(1 / C_{\mathrm{T}}\right)[?] C_{\mathrm{i}} \ln \left(C_{\mathrm{T}} / C_{\mathrm{i}}\right)=[?] x_{\mathrm{i}} \ln \left(1 / x_{\mathrm{i}}\right)(5)$

$f / C_{\mathrm{T}}=\ln \left(N_{\mathrm{m}}\right)-s / C_{\mathrm{T}}=\ln (66)-s / C_{\mathrm{T}}(6)$

where $c_{\text {ij }}$ denotes the net dry biomass quantity of the jth plant for the ith species, $C$ i denotes the total net dry biomass quantity of the ith species, $C_{\mathrm{T}}$ denotes the total net dry biomass quantity of the plant community, $x_{\mathrm{i}}$ denotes the mass ratio for the ith species, and $N_{\mathrm{m}}$ stands for the maximum number of plant species (Eqs. 2-4 referring to Eqs. 11-13, 24 in the theoretical section). As an upper limit of $N, N_{m}$ for a given habitat is a constant. The enthalpy factor $h$ is a linear function of $C_{T}$ and use of any $N_{m}$ value will not change its basic relation with the Gibbs free energy factorf and entropy factor $s$. Since, as a potential limit, $N_{m}$ is a parameter related to regional species richness, the highest number of plant species 66 observed in the non-polluted surrounding area nearby the metal contaminated site was used as $N_{m}$ for calculating $h$.

For comparing the difference among plant species, the standard deviation for relevant parameters was calculated by

$S D=[?]\left[\left(Z_{\mathrm{i}}-Z\right)^{2} /(N-1)\right]^{1 / 2} \mathrm{Z}=[?] Z_{\mathrm{i}} / N$

where $Z_{\mathrm{i}}$ denotes a parameter for the ith species and $\mathrm{Z}$ denotes its mean value.

\section{Results and analysis}

Dynamic changes in the restoration process

The total net dry biomass $C_{\mathrm{T}}$ and total number of species $N$ of the plant communities in Plots I (amended with organic manure), II (amended with chemical fertilizer) and III (uncontaminated site) obtained in the period 2010 - 2016 are given in Table 1. Basic data for plant species are presented in Appendix 1. The values of $h, s, f, s / C_{\mathrm{T}}$ and $f / C_{\mathrm{T}}$ in Table 1 were calculated, respectively, by Eqs. 2-6. As a record of the restoration process history of the plant community, the data show the dynamic changes in its ecological and thermodynamic states. The effect of the applied restoration method has been partly discussed in previous papers (Wu et al., 2017; 2018). Some of the main results are briefly summarized below:

(1) The applied methods had not only enhanced the biomass growth and metal uptake of the plant community but also enriched its species composition (Table 1, Appendix 1). In the later period, both $C_{\mathrm{T}}$ and $N$ of the plant community in Plot I (amended with organic manure) were all several folds greater than those 
in Plot II (amended with chemical fertilizers) and their differences were highly significant $(\mathrm{P}<0.01)$. In addition to supply of nutrients and improvement of soil properties, the remediation effect of the organic manure was mainly attributed to its incorporation with plant roots, microorganism and substrates, forming an integrated system of chelation, oxidation, adsorption and absorption in reduction of the metal toxicity in the rhizosphere. The significant differences in $C_{\mathrm{T}}$ and $N$ between years 2015 and 2016 in Plot I indicated that the plant community was still undergoing fast development. The species enrichment in both Plots I and II after land preparation was attributed to the natural germination of the native metal-tolerant species from the soil seed inventory while the difference in $N$ between plots was mainly caused by the applied fertilizers.

(2) The highest $N$ value 66 was observed in Plot III for the plant community naturally developed under uncontaminated soil conditions (Table 1). The $C_{\mathrm{T}}$ value in Plot III was much lower than that in plot I and the difference was attributed to the significant contribution of the transplanted $P$. fortunei and $K$. bipinnata in plot I. The total metal uptake quantities for all measured metals were very low in Plot III (Wu et al., 2018) and the correlation between its biomass quantity and metal uptake was insignificant $\left(\mathrm{R}^{2}<0.20\right)$, indicating that metal toxicity was not the factor limiting the plant growth. The species number $N$ in Plot III remained unchanged in years 2015 and 2016 and the difference in $C_{\mathrm{T}}$ between these two years was insignificant (Table 1 ), showing that the plant community had reached a relatively steady state.

It is noted in Table 1 that the thermodynamic factors, $h, s, f$ and $s / C$, all increased with time in both Plots I and II with $f / C$ T as a unique exception. Unlike $h$, which is independent of $N$, boths and $f$ are functions of $C{ }_{\mathrm{T}}$ and $N$. If $s$ reaches its maximum, $s=s \mathrm{~m}=C_{\mathrm{T}} \ln (N)$ (Eq. 19 in theoretical section), Eq. 6 becomes

$f / C_{\mathrm{T}}=\ln \left(N_{\mathrm{m}}\right)-s / C_{\mathrm{T}}=\ln \left(N_{\mathrm{m}}\right)-\ln (N)(8)$

showing that $f / C$ T will decrease while $s / C$ T will increase with increasing $N$. The observed changes in $f / C$ ${ }_{\mathrm{T}}$ and $s / C_{\mathrm{T}}$ were thus expected results, indicating that $N$ is the key factor that governs the internal energy flow and distribution. Since the inverse relationship between $f / C_{\mathrm{T}}$ and $s / C_{\mathrm{T}}$ holds in nature, Eqs. 6 and 8 can be applied to analyze the productivity-species richness relationship.

\section{Contribution of plant species}

The contributions of $P$. fortunei and K. bipinnata to relevant indices are compared in Table 2 . The two transplanted species were shown to be fast-growing tree species with high growth and metal uptake rates under the improved site conditions. The sum of their number of individual plants in Plot I was only $0.104 \%$ of that of the plant community while that of their biomass, Mn uptake and land coverage contributed, respectively, $84.77 \%, 67.63 \%$ and $56.30 \%$ to the plant community. The high contribution percentage of the two species to $s, h$ and $f$ showed their importance in matter and energy transformation and conservation (Table 2).

Positive correlations between biomass and uptake of all measured metal elements among species were observed in both Plots I and II at high levels of significance $\left(\mathrm{R}^{2}>0.95\right)(\mathrm{Wu}$ et al., 2018), indicating that the accelerated growth of the plant community enhanced its metal uptake rates. Accordingly, the significant contribution of the transplanted species to total metal uptake was accounted for by their high growth rates. In comparison, the average contents of $\mathrm{Mn}$ in P. fortunei and K. bipinnata $(0.1302,0.1530 \mathrm{mg} / \mathrm{g}$, calculated using the data in Appendix 1) were much lower than that in Radix Phytolaccae $(0.9990 \mathrm{mg} / \mathrm{g})$ in Plot I. The average net dry biomass quantity per plant of the two tree species $(31.77,2.23 \mathrm{~kg})$ was, respectively, 369.5 and 25.92 times higher than that of $R$. Phytolaccae $(0.0860 \mathrm{~kg})$, and their average Mn uptake per plant $(4.1373,0.3410 \mathrm{~g})$ was thus 48.16 and 3.97 times higher than that of this commonly acknowledged hyper-accumulator (0.0859 g) (Xua et al., 2015; Zhang et al., 2015).

The key factor that led to the differences in $C$ таnd $N$ between Plots I and II was the type of applied fertilizers. However, as the organic manure was only addressed to the rooting area of the transplanted species in Plot I for reducing the remediation cost (Wu et al., 2017), the rapid increase in the number of native plant species spreading over the entire area of Plot I suggested that the root growth and metabolic 
activities of the transplanted species and decomposition of their fallen branches and leaves had also played important roles in promoting the growth of other native species and enhancing the species richness of the plant community particularly in later years.

Despite their important functions as dominant species in the restored plant community, the contributions of $P$. fortunei and $K$. bipinnata to the Shannon-Wiener index $S I$ were extremely low and the sum of their percentage values was less than $0.3 \%$ (Table 2). The $S I$ index (Eq. 1) is a single function of the number of individual plants $m_{\mathrm{i}}$ while the sum of the survived number of individual plants of the two transplanted tree species $\left(1700 / \mathrm{hm}^{2}\right.$, Appendix 1) was negligible compared to the total individual number of the community $\left(1633974.9 / \mathrm{hm}^{2}\right)$, giving thus extremely low $S I_{\mathrm{i}}$ or $p_{\mathrm{i}}$ values for these two tree species. This means that the $S I_{\mathrm{i}}$ index will not take into account the important roles of the dominant species if they have small individual numbers.

Another phenomenon depicted in Fig. 1. was that the contribution percentage of the two transplanted species to $C_{\mathrm{T}}$ (Fig. 1a) and $M$ (Fig. 1b) decreased while that of the other species increased with increasing $N$. The contribution percentage of a species to $C_{\mathrm{T}}$ or $M$ is equal to its $x$ i (biomass ratio) or $p_{\mathrm{i}}$ (individual number ratio) given in percentage. The curves in Fig. 1 thus show clearly the negative effect of species richness $(N)$ and abundance $(M)$ on $x_{\mathrm{i}}$ and $p_{\mathrm{i}}$ of the transplanted tree species.

Difference between thermodynamic entropy and information entropy

It is noticed in Table 2 that the highest $S I$ value was 2.97 observed for Plot I, followed by 2.86 for Plot III and 1.75 for Plot II. It is understandable for Plot II to have the lowest $S I$ value but it is not fully explicable for Plot I to have a higher SI than Plot III. As a commonly applied biodiversity index, SI is thought to be presented as a function of species richness and evenness (Molles, 2016), namely that the higher the level of species richness and evenness, the higher the level of biodiversity. Compared to Plot I, Plot III had a higher maximum $S I \mathrm{~m}=\ln (N)$ associated with much lower standard deviation $S D$ values for $C_{\mathrm{TB}}, C{ }_{\mathrm{TU}}, C o v, s$ ,$h$ and $f$ among the species of the community (Table 2). As a statistical parameter given by Eq. 7, $S D$ can be used as an indicator for species evenness. The trend will be that the lower the $S D$ value, the higher the species evenness in related physical quantities. As seen in Table 2, the $S D$ values for $C{ }_{\mathrm{TB}}, C_{\mathrm{TU}}, C o v, s$, $h$ and $f$ were all in confirmative with the on-site field sensation that Plot III had a higher level of species richness and evenness than Plot I. The unique factor left that actually lowered the SI value of Plot III was its highly significant difference in the number of individual plants $m$ iamong species as being indicated by the largest $S D$ value for $M$ (Table 2).

The significant differences between $S I_{\mathrm{i}}$ and $s_{\mathrm{i}}$ crossing plant species are illustrated in Fig. 2 using the data obtained from the year 2016. The number on the horizontal axis in Fig 2 corresponds to the rank number of species (ranked in an ascending order of $m_{\mathrm{i}}$ or $S I_{\mathrm{i}}$ ) listed in Appendix 1. The generally observed trend was that a great number of species possessing lower $S I$ i values had relatively higher $s_{\mathrm{i}}$ values. The typical case in Plot I depicted in Figs. 2a was that the two transplanted tree species (P. fortunei and K. bipinnata) had extremely low $S I_{\mathrm{i}}$ values $(0.0038 ; 0.0040)$ associated with the highest $s_{\mathrm{i}}$ values $\left(6.2368 ; 5.5120 \mathrm{ton} / \mathrm{hm}^{2}\right)$. The species that had the highests i value was P. acinosa $\left(0.5142 \mathrm{ton} / \mathrm{hm}^{2}\right)$ in Plot II (Fig. 2b) and $B$. papyrifera $\left(3.4985\right.$ ton $\left./ \mathrm{hm}^{2}\right)$ in Plot III (Fig. 2c) but their $S I_{\text {i }}$ values $(0.1306 ; 0.1105)$ were relatively low. The two transplanted species were not the strongest competitors under natural conditions in this region. Among the native species in Plot III, B. papyrifera was found to be the one possessing the highest $s_{\text {i }}$ value though its $S I_{\mathrm{i}}$ value was comparably low (Fig. 2c).

The inconsistence of the variation in $m_{\mathrm{i}}$ and $C_{\mathrm{i}}$ among species is the reason for the difference between $S I_{\mathrm{i}}$ and $s_{\mathrm{i}}$ given, respectively, as $\left(m_{\mathrm{i}} / M\right) \ln \left(M / m_{\mathrm{i}}\right)$ (Eq. 1) and $C_{\mathrm{i}} \ln \left(C_{\mathrm{T}} / C_{\mathrm{i}}\right)$ (Eq. 3). Since most species possessing high $C$ ivalues in Plot I had relatively low $m_{\text {i }}$ values, the levels of the correlations of $s, h$ and $f$ with $S I$ crossing species were extremely low as indicated by their correlation coefficient $R$ values (Table 2 ). The reason for the slightly higher $R$ values of the correlations between SI and $s$ in Plots II and III was attributed to their lower $S D$ values in $C_{\text {i }}$ among species.

The present study does not give full support to use of $S I$ as a biodiversity index for describing the investigated 
plant communities simply because $S I$ is a single function of the individual plant number. Biodiversity of an ecosystem should be in principle a macroscopic property or a state function of the ecosystem describing the state of its composition and structure linked to its matter and energy transformation. The $s$ factor defined by Eq. 3 meets this criterion as a biodiversity index as it is not a probability variable but a state function interrelated with another two thermodynamic factorsh and $f$. It is noted in Table 2 that though the $C_{\mathrm{T}}$ value was much higher in Plot I than in Plot III, the $s$ value of Plot I $\left(34.77 \mathrm{ton} / \mathrm{hm}^{2}\right)$ was still lower than that of Plot III (35.05 ton $\left./ \mathrm{hm}^{2}\right)$. This was in agreement with what was observed in the field that Plot I had a higher level of biomass productivity while Plot III had a higher level of biodiversity.

Difference between entropy and maximum entropy

As illustrated in Fig. 3, the ratio of the entropy factor to total mass quantity $s / C{ }_{\mathrm{T}}$ was positively related to $\ln (N)$ at high levels of correlation in both Plots $\mathrm{I}\left(\mathrm{R}^{2}=0.9449\right.$, Fig. 3a) and II $\left(\mathrm{R}^{2}=0.9950\right.$, Fig. $3 \mathrm{~b})$. Sinces $s_{\mathrm{m}} / C_{\mathrm{T}}=\ln (N)$, the difference between the observed $s / C_{\mathrm{T}}$ and $\ln (N)$ was resulted from the difference between $s$ and its maximum $s \mathrm{~m}$. Combining the linear regression equation with Eq. 5 gives

$s / C_{\mathrm{T}}=[?] x_{\mathrm{i}} \ln \left(1 / x_{\mathrm{i}}\right)=a \ln (N)=a\left(s_{\mathrm{m}} / C_{\mathrm{T}}\right)(9)$

The logical variation range of the proportional factor $a$ will be 0 [?] $a$ [?] 1 as $a=0, s / C_{\mathrm{T}}=\ln \left(N^{0}\right)=$ 0 , which is a special case for a single species system while $a=1, s / C_{\mathrm{T}}=\ln (N)=s \mathrm{~m} / C_{\mathrm{T}}$, which is the potential limit at which $s$ reaches its maximum $s$.

The increase in $s / C$ T with increasing $\ln (N)$ is a process of increase in species richness while the approach of $s$ to $s \mathrm{~m}$ is a process of increase in species evenness. The proportional factor $a$ can thus be regarded as an index for species evenness. The higher value of $a$ found for Plot II (0.7059) than that for Plot I (0.2218) indicated that the level of species evenness was much higher in Plot II than in Plot I. The cause for the smaller difference between $s$ and $s \mathrm{~m}$ in Plot II was its metal contaminated condition that inhibited the growth of the species and reduced the difference among them.

\section{Discussions}

Spontaneous changes

Because of matter and energy input, the growth and development of a plant community should be in principle a natural process characterized by spontaneous increases in its total biomass quantity $C_{\mathrm{T}}$ and total number of plant species $N$. The enthalpy $H$, Gibbs free energy $G$ and entropy $S$ of a plant community are state functions all positively related to $C$ T and $N$. Their increments, ${ }^{H},{ }^{G}$ and ${ }^{S}$ shouldbegreaterthanzerosubjectto ${ }_{\mathrm{T}}>0$ and $^{N}>0$. SuchchangesshownbytheexperimentaldatainTable 1 thus followed

In contrast, the observed decrease in $f / C_{\mathrm{T}}$ due to increase in $s / C$ T with increasing $N$ (Table 1 ) obeys the $2^{\text {nd }}$ law of thermodynamics that the spontaneous change in the state of a system is an irreversible process towards the direction of decrease in its intensity factor (Engel \& Reid, 2006). For a given system, $\ln (N$ ) and $\ln \left(N_{\mathrm{m}}\right)$ are intensity factors related to the average chemical potential $\mu$, weighted standard chemical potential $\mu^{0}$ and average mass ratio $x$, respectively, by

[?]f $/[?] C_{\mathrm{T}}=[?] h /[?] C_{\mathrm{T}}-[?] s_{\mathrm{m}} /[?] C_{\mathrm{T}}=\mu /(\mathrm{RT})=\mu^{0} /(\mathrm{RT})-\ln (1 / x)=\ln \left(N_{\mathrm{m}}\right)-\ln (N)(10)$

(Eq. 25 in the theoretical section). Given temperature $T, \ln (N \quad \mathrm{~m})$ is a constant while increasing $N$ will reduce $x$ since $x=1 / N$. We shall have

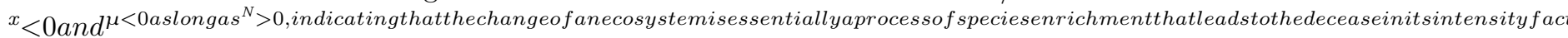

The observed changes in $s / C_{\mathrm{T}}$ and $f / C_{\mathrm{T}}$ (Table 1) also obeys the $3^{\text {rd }}$ law of thermodynamics regarding the principle of entropy increase (Engel \& Reid, 2006). As been discussed in the previous paper, there can be two spontaneous changes related to entropy increase, of which one is increasing $s$ with increasing $N$ and the other one is increasing $s$ towards $s$ m at a given $N$. The general trend of increasing $s$ with increasing $N$ is clearly demonstrated by the positive correlation between $s / C_{\mathrm{T}}$ and $\ln (N)$ in Fig. 3. The decrease in the mass ratio of the transplanted species with increasing $N$ illustrated in Fig. 1a shows the potential trend of 
increasing $s$ towards $s \mathrm{~m}$. The increase in the contribution of new species naturally geminated in the plot to the total biomass quantity $C_{\mathrm{T}}$ reduced the contribution ratio of the dominant species, which in turn reduced the difference between the peak $x_{\mathrm{i}}$ and average $x$. In accordance with the maximum entropy theorem, $s=$ $s \mathrm{~m}_{\mathrm{m}}$ at $x_{\mathrm{i}}=x_{\mathrm{j}}=x=1 / N, s$ will get closer to $s \mathrm{~m}_{\mathrm{m}}$ at higher $N$ levels subject to the constraint [?] $x_{\mathrm{i}}=1$.

The fact that increasing $N$ is the essential cause for $\mu<0$ makes $^{N}>0$ ausefulindicatorforjudgingthespontaneityofanecologicalprocessasitistec

System diversity

The $S I$ data listed in Table 2 do not fully prove the use of the traditional applied Shannon-Wiener index $S I$ for comparing the biodiversity among the investigated plant communities. The patterns in Fig. 2 indicate that $S I_{\mathrm{i}}$ is not a proper parameter for species abundance in terms of mass quantity and internal energy. There is a theoretical flaw to use $S I$ as a biodiversity index for description of an ecosystem simply because the biodiversity of an ecosystem is not a single function of the number of individuals $m_{\mathrm{i}}$ or its ratio $p_{\mathrm{i}}$. According to the principle of invalidity of a single factor, a system state cannot be determined by a single factor unless some of other factors are kept constant. The relative abundance of a species on a habitat cannot thus be uniquely determined by $m$ iunless the individuals both within and across species are identical, or at least, with no significant differences in their concerned physical properties and quantities. As a matter of fact, use of $p_{i}$ as a relative abundance index also disobeys the principle of additivity. The number of individuals of a herb species cannot be added to that of a tree species simply because a small grass is hardly comparable to a big tree with respect to their ecological functions in a plant community. The value of $M$ would be in particular meaningless at an ecosystem approach if it should stand for the total number of individuals of all organisms co-existed in the ecosystem.

Unlike $S I$, which is a single function of individual number ratio $p_{\mathrm{i}}, s$ is a function of mass quantity $C_{\mathrm{i}}$ and mass ratio $x_{\mathrm{i}}$. As been discussed in the theoretical section, the rationality for calculating $x_{\mathrm{i}}$ is based on the assumption that the biomass of different plant species possesses the same unit energy value in terms of standard chemical potential. If this criterion is not fulfilled, the weighted biomass quantity $C_{\text {ir should be }}$ used for calculating the total equivalent mass quantity $C_{\mathrm{T} \gamma}$. As a state function (rather than a probability variable), $s$ is a system property linked to system composition, and can thus be generally applied as a system diversity index. Use of $s$ for determining the diversity state of a system also follows the principle of relative validity of a single factor. From Eq. 5 , we see that $\ln \left(N_{\mathrm{m}}\right)$ is a constant, and given $C_{\mathrm{T}}$, both $f$ and $s$ can be uniquely determined by $x_{\mathrm{i}}$. The analytical results obtained in the present study give support to use of $s$ as a system diversity index (Tables 1 and 2, Fig 2). Since the related principle holds in general with no exceptions, $s$ can be used as a diversity index for all types of thermodynamic systems.

It is necessary to mention that $S I$ can be a useful index in particular cases. Apart from that $S I$ does not differ from $s / C_{\mathrm{T}}$ in both concept and quantity in systems with uniform individuals (see discussions in the theoretical section), the number of individuals $m_{\mathrm{i}}$ or $S I_{\mathrm{i}}$ is a meaningful index to reflect the ability of a species to reproduce at a given habitat. The $S I$ i patterns for different plots depicted in Fig. 2 show its importance for comparing the ability of species to survive under different site conditions. Reproduction is also an energy consumption process. It should take a longer time for a tree species with a larger body size to multiply its individual number since more energy is required in its reproduction.

\section{Conclusions}

(1) The change in the state of the restored plant community with time was an irreversible process characterized by spontaneous increase in its total biomass quantity $C_{\mathrm{T}}$ and total number of plant species $N$ associated with increase in its enthalpy $H$, Gibbs free energy $G$ and entropy $S$. Species enrichment was the cause for the decease in mass ratio $x_{\mathrm{i}}$ and biomass growth potential $\mu_{\mathrm{i}}$. The changes in the thermodynamic factors $f / C$ T and $s / C_{\mathrm{T}}$ due to decrease in $x_{\mathrm{i}}$ with increasing $N$ followed the basic laws of thermodynamics. The criterion ${ }^{N}>0$ canbegenerallyappliedasanindex fordeterminingthedirectionof spontaneouschangesinanopenthermodynamicsystemu

(2) The conducted analysis did not fully prove the use of the Shannon-Wiener index as a biodiversity index for the investigated plant communities. The biodiversity of a plant community cannot be determined by the 
number of individuals if there are significant differences in individuals among species of the plant community. In contrast, the entropy factor $s$ was proven to be a suitable diversity index. As a state function related to system composition, $s$ can be applied as a diversity index for all types of systems.

\section{Acknowledgement}

The present study forms part of the projects supported by the Ministry of Environmental Protection [200909066] and the Ministry of Science and Technology [2012GS430203], P. R. China.

\section{Conflict of interest}

None declared.

\section{Author Contributions}

Mingli Chen and Xiaofu Wu designed the study. Xinxi Fu and Zijian Wu conducted the statistical analysis and wrote the first draft of the manuscript. All authors contributed substantially to revision, field sampling and Lab analysis.

\section{Data accessibility}

The authors agree to deposit their data to a public repository. The basic experimental data used in the analyses have been presented in Appendix 1.

\section{References}

Abreu, M. M., Santos, E. S., Magalhaes, C. F. \& Fernandes, E. (2012). Trace elements tolerance, accumulation and translocation in Cistus populifolius, Cistus salviifolius and their hybrid growing in polymetallic contaminated mine areas. Journal of Geochemical Exploration, 123, 52-60.

Adamo, P., Lavazzo, P., Albanese, S. \& Agrelli, D. (2014). Bioavailability and soil-to

-plant transfer factors as indicators of potentially toxic element contamination in agricultural soils. Science of the Total Environment, 500, 11-12.

Baldera, A., Hanson, D. A. \& Kraft, B. (2018). Selecting indicators to monitor

outcomes across projects and multiple restoration programs in the Gulf of Mexico. Ecological Indicators, $89,559-571$.

Bidwell, S. D., Woodrow, I. E., Batianof, F. G. N., et al. 2002. Hyperaccumulation of manganese in the rainforest tree Austromyrtus bidwillii (Myrtaceae) from Queensland, Australia. Functional Plant Biology, 29, 899-905.

Engel, T. \& Reid, P. (2006). Physical Chemistry, Pearson Benjamin Cummings, New

York, USA, pp 117; 126; 195.

Fiedler, S., Perring, M. P. \& Tietjen, B. (2018). Integrating trait-based empirical and

modeling research to improve ecological restoration. Ecology and Evolution,

8, 6369-6380.

García. M., Alonso, J. \& Melgar, M. J. (2009). Lead in edible mushrooms Levels and bioaccumulation factors. Journal of Hazardous Materials, 167, 777-783.

Garrouj, M., Alard, D. Corcket, D., Marchand, L. \& Benot, M. (2019). The effects of management on vegetation trajectories during the early-stage restoration of previously arable land after hay transfer. Ecology and Evolution, 9,

13776-13786. 
Gomez-Ros, J.M., Garcia, G. \& Penas, J. M. (2013). Assessment of restoration success of former metal mining areas after 30 years in a highly polluted Mediterranean mining area: Cartagena-La Unión. Ecological Engineering, 57, 393-402.

González, E., Rochefort, L., Boudreau, S. \& Poulin, M. (2014). Combining indicator

species and key environmental and management factors to predict restoration success of degraded ecosystems. Ecological Indicators, 46, 156 -166.

Haapalehto, T., Juutinen, R. Kareksela, S. Kuitunen, M., Tahvanainen, T., Vuori, H. \&

Kotiaho, J. S. (2017). Recovery of plant communities after ecological restoration

of forestry-drained peat lands. Ecology and Evolution, 7, 7848-7858.

Harte, J. \& Newman, E. A. (2014). Maximum information entropy: a foundation for ecological theory. Trends Ecol. Evol, 29, 384-389.

Hesse, E., O’Brien, S., Tromas, N., Bayer, F., Lujan, A. M., van Veen, E. M., Hodgson, D. J. \& Buckling, A. (2018). Ecological selection of

siderophore-producing microbial taxa in response to heavy metal contamination.

Ecology Letters, 21, 117-127.

Jørgensen, S.E. (2010). Ecosystem services sustainability and thermodynamic indicators. Ecosystem Complexity, $7,311-313$.

Jørgensen, S.E., Nielsen, S.N. \& Fath, B. D. (2016). Recent progress in systems ecology. Ecological Modelling, 319, 112-118.

Kollmann, J. \& Mahy, G. (2018). Towards a population approach for evaluating grassland restoration - a systematic review. Restoration Ecology, 26(2), 227-234.

Laner, D., Zoboli, O. \& Rechberger, H. (2017). Statistical entropy analysis to evaluate resource efficiency: Phosphorus use in Austria. Ecological Indicators, 83, 232-242.

Laughlin, D. C. (2014). Applying trait-based models to achieve functional targets for theory-driven ecological restoration. Ecology Letters, 17, 771-784.

Ludovisi, A. \& Scharler, U. M. (2017). Towards a sounder interpretation of entropy-based indicators in ecological network analysis. Ecological Indicators, 72, 726-737.

Molles, M. C. (2016). Ecology concept and application. Seventh edition,

McGraw-Hill Education, New York, USA, pp. 197-271; 352-371; 484-505.

Newman, E. A., Harte, M. E., Lowell, N., Wilber, M. \& Harte, J. (2014). Empirical tests of within- and across-species energetics in a diverse plant community. Ecology, 95(10), 2815-2825.

Ouyang, L., Wu, X., Li, Y., Feng, C. \& Chen, Y. (2016). Growth and heavy metal accumulation of Paulownia fortunei andKoelreuteria bipinnata in an ecological restoration site of the manganese-ore tailing. China Environmental Science, 36(3), 908-916.

Ricklefs, R. \& Relyea, R. (2014). Ecology the economy of nature. W.H. Freeman and

Company. Seventh edition, New York, USA, pp.466-489; 514-539. 
Tang, Y., Cao, M. \& Fu, X. H. (2006). Soil seedbank in a dipterocarprain forest in Xishuangbanna, Southwest China. Biotropica, 38(3), 328-333.

Tie, B. Q., Yuan, M. \& Tang, M. Z. (2005). Phytolacca Americana L.: a new manganese accumulator plant. Journal of Agro-Environment Science, 242, 340-343.

Tongkoom, K., Marohn, C.H., Piepho, P. \& Cadisch, G. (2018). Ecosystem recovery

indicators as decision criteria on potential reduction of fallow periods in swidden systems of Northern Thailand. Ecological Indicators, 95, 554-567.

Vargas-García, M. D. C., López, M. J., Suárez-Estrella, F., et al. (2012). Compost as a source of microbial isolates for the bioremediation of heavy metals: Invitro selection. Science of the Total Environment, 431, $62-67$.

Wallace, K. J., Laughlin, D. C. \& Clarkson, B. D. (2017). Exotic weeds and

fluctuating microclimate can constrain native plant regeneration in urban forest restoration. Ecological Applications, 27(4), 1268-1279.

Wang, J., Li, W. H., Zhang, C. B., et al. (2010). Physiological responses and detoxific mechanisms to Pb, Zn, $\mathrm{Cu}$ and $\mathrm{Cd}$ in young seedlings of Paulownia fortune. Journal of Environmental Sciences, 22(12), 1916-1922.

Wu, Z., Wu, X., Yang, Z. \& Ouyang, L. (2017). A simple thermodynamic model for

evaluating the ecological restoration effect on a manganese tailing wasteland. Ecological Modelling, 346, $20-29$.

Wu, Z., Wu, X., Yang, Z. \& Ouyang, L. (2018). Internal energy ratios as ecological

indicators for description of the phytoremediation process on a manganese tailing site. Ecological Modelling, $374,14-21$.

Xua, X., Yang, J., Zhao, X., Zhang, X. \& Li, R. (2015). Molecular binding

mechanisms of manganese to the root cell wall of Phytolacca americana L. using

multiple spectroscopic techniques. Journal of Hazardous Materials, 296,

$185-191$.

Yang, S. X,, Deng, H. \& Li, M. S. (2008). Manganese up take and accumulation in a woody hyperaccumulator, Schimasuperba. Plant Soil and Environment, 54(10), 441-446.

Yang, Z. H., Wu, Z. J., Liao, Y. P., et al. (2017). Combination of microbial oxidation and biogenic schwertmannite immobilization: A potential remediation for highly arsenic-contaminated soil. Chemosphere, 181:1-8.

Zhang, W., Chen, W., He, L., Wang, Q. \& Sheng, X. (2015). Characterization of Mn-resistant endophytic bacteria from Mn-hyper- accumulator Phytolacca americana and their impact on Mn accumulation of hybrid penisetum. Ecotoxicology and Environmental Safety, 120, 369-376.

Zhao, Q., Bai, J., Huang, L., Gu, B., Lu, Q. \& Gao, Z. (2016). A review of

methodologies and success indicators for coastal wetland restoration. Ecological

Indicators, 60, 442-452.

Table 1 Total net dry biomass $C{ }_{\mathrm{T}}\left(\mathrm{kg} / \mathrm{hm}^{2}\right)$, total number of species $N$ and thermodynamic factors $(h, s$ and $f$, ton $/ \mathrm{hm}^{2}$ ) of the investigated plant communities (Plot I: tailing site amended with organic manure; Plot II: tailing site amended with chemical fertilizers; Plot III: uncontaminated site; $h, s, f, s / C{ }_{\mathrm{T}}$ and $f / C$ T: calculated, respectively, by Eqs. 2-6). 


\begin{tabular}{|c|c|c|c|c|c|c|c|c|}
\hline Plot & Year & 2010 & 2011 & 2012 & 2013 & 2014 & 2015 & 2016 \\
\hline \multirow[t]{7}{*}{ I } & $C_{\mathrm{T}^{*}}{ }^{2}$ & $259.2 \pm 21.3$ & $566.2 \pm 65.7$ & $2187.4 \pm 229.7$ & $7763.2 \pm 869.5$ & $14915.2 \pm 2013.6$ & $23324.0 \pm 2752.2$ & $33498.7 \pm 3$ \\
\hline & $N$ & 5 & 8 & 17 & 36 & 44 & 48 & 51 \\
\hline & $h$ & 1.085 & 2.37 & 9.165 & 32.53 & 62.5 & 97.75 & 140.35 \\
\hline & $s$ & 0.092 & 0.26 & 1.33 & 5.63 & 11.2 & 20.01 & 34.77 \\
\hline & $f$ & 0.993 & 2.11 & 7.835 & 26.9 & 51.3 & 77.74 & 105.58 \\
\hline & $s / C_{\mathrm{T}}$ & 0.3549 & 0.4592 & 0.6080 & 0.7252 & 0.7509 & 0.8579 & 1.0380 \\
\hline & $f / C_{\mathrm{T}}$ & 3.8310 & 3.7266 & 3.5819 & 3.4651 & 3.4394 & 3.3330 & 3.1518 \\
\hline \multirow[t]{7}{*}{ II } & $C_{\mathrm{T}}$ & $75.2 \pm 8.8$ & $134.2 \pm 10.9$ & $267.1 \pm 30.2$ & $475.2 \pm 48.5$ & $786.7 \pm 80.2$ & $1132.6 \pm 107.6$ & $1468.8 \pm 171$ \\
\hline & $N$ & 5 & 5 & 7 & 8 & 11 & 13 & 15 \\
\hline & $h$ & 0.315 & 0.56 & 1.12 & 1.99 & 3.295 & 4.745 & 6.2291 \\
\hline & $s$ & 0.084 & 0.151 & 0.36 & 0.69 & 1.39 & 2.100 & 2.733 \\
\hline & $f$ & 0.231 & 0.409 & 0.76 & 1.3 & 1.905 & 2.645 & 3.4961 \\
\hline & $s / C_{\mathrm{T}}$ & 1.1170 & 1.1252 & 1.3478 & 1.4520 & 1.7669 & 1.8541 & 1.8607 \\
\hline & $f / C_{\mathrm{T}}$ & 3.0718 & 3.0477 & 2.8454 & 2.7357 & 2.4215 & 2.3353 & 2.3802 \\
\hline \multirow[t]{7}{*}{ III } & $C_{\mathrm{T}}$ & & & & & & $9983.5 \pm 902.1$ & $10884.9 \pm 87$ \\
\hline & $N$ & & & & & & 66 & 66 \\
\hline & $h$ & & & & & & 83.66 & 91.21 \\
\hline & $s$ & & & & & & 31.54 & 35.06 \\
\hline & $f$ & & & & & & 52.12 & 56.15 \\
\hline & $s / C T$ & & & & & & 0.3159 & 0.3221 \\
\hline & $f / C T$ & & & & & & 0.5221 & 0.5159 \\
\hline
\end{tabular}

*: Significant difference in $C_{\mathrm{T}}$ between Plots I, II and III: $\mathrm{P}<0.01$

Table 2 Contribution percentage (C.P. ) of P. fortunei and K. bipinnata to total net dry biomass $(C$ TB, $\mathrm{kg} / \mathrm{hm}^{2}$ ), total $\mathrm{Mn}$ uptake $\left(C \mathrm{TU}, \mathrm{g} / \mathrm{hm}^{2}\right)$, total number of individual plants $(M)$, Coverage (Cov .), Shannon-Wiener index $(S I)$ and thermodynamic factors $\left(s, h\right.$ and $\left.f, \operatorname{ton} / \mathrm{hm}^{2}\right)$; standard deviation $(S D)$; and coefficient $(R)$ of correlations of $s, h$ and $f$ with $S I$ (Data: Year 2016)

\begin{tabular}{llllllllll}
\hline Plot & Index & $C_{\mathrm{TB}}$ & $C_{\mathrm{TU}}$ & $M$ & $C o v$ & $S I$ & $s$ & $h$ & $f$ \\
\hline I & & 33498.7 & 5532.6 & 1633974.9 & 298.0 & 2.970 & 34.77 & 140.35 & 105.57 \\
II & Total & 1468.8 & 2116.2 & 1449607.8 & 70.08 & 1.752 & 2.716 & 6.229 & 3.513 \\
III & & 10884.9 & 698.4 & 11603893.4 & 316.4 & 2.86 & 35.05 & 91.21 & 56.16 \\
I & & 84.77 & 67.63 & 0.1040 & 56.30 & 0.2648 & 33.79 & 84.77 & 87.20 \\
II & C.P. (\%) & - & - & - & - & - & - & - & - \\
III & & 2.293 & 1.610 & 0.0023 & 0.7585 & 0.0090 & 3.1689 & 2.2933 & 1.7467 \\
I & & 3704.6 & 483.2 & 61177.4 & 16.87 & 0.0688 & 1.3449 & 15.52 & 14.92 \\
II & \multirow{2}{*}{ SD } & 184.3 & 334.4 & 166994.8 & 7.7928 & 0.1186 & 0.1377 & 0.7724 & 0.6628 \\
III & & 328.8 & 17.3 & 391331.8 & 6.4990 & 0.0695 & 0.6470 & 2.7547 & 2.1502 \\
I & & & & & & & -0.0197 & -0.1136 & -0.1185 \\
II & \multirow{2}{*}{ III } & & & & & & 0.4603 & 0.0672 & -0.0173 \\
III & & & & & & & 0.4517 & 0.3281 & 0.2845 \\
\hline
\end{tabular}

*: Standard deviation $S D$ was calculated by Eq. 7.

Appendix $1\left(C_{\mathrm{B}}\right.$ : biomass quantity, $\mathrm{kg} / \mathrm{hm}^{2} ; C_{\mathrm{U}}$ : Mn uptake, $\mathrm{g} / \mathrm{hm}^{2} ; m$ : number of individuals. Rank No: arranged in an ascending order of $m$ corresponding toSI ${ }_{i}$ in Fig. 2. Data: Year 2016) 


\begin{tabular}{|c|c|c|c|c|c|}
\hline Rank No & Plot I & Plot I & $C_{\mathrm{B}}$ & $C_{\mathrm{B}}$ & $C_{\mathrm{B}}$ \\
\hline 1 & Ixeris denticulata & Ixeris denticulata & 12.57 & 12.57 & 12.57 \\
\hline 2 & Achyranthes bidentata & Achyranthes bidentata & 2.94 & 2.94 & 2.94 \\
\hline 3 & Pharbitis nil & Pharbitis nil & 9.44 & 9.44 & 9.44 \\
\hline 4 & Paulownia fortunei & Paulownia fortunei & 26465.71 & 26465.71 & 26465.71 \\
\hline 5 & Koelreuteria bipinnata & Koelreuteria bipinnata & 1932.07 & 1932.07 & 1932.07 \\
\hline 6 & Pterocypsela formosana & Pterocypsela formosana & 18.98 & 18.98 & 18.98 \\
\hline 7 & Kummerowia striata & Kummerowia striata & 2.23 & 2.23 & 2.23 \\
\hline 8 & Chenopodium ambrosioides & Chenopodium ambrosioides & 99.65 & 99.65 & 99.65 \\
\hline 9 & Mazus japonicus & Mazus japonicus & 2.15 & 2.15 & 2.15 \\
\hline 10 & Imperata cylindrica & Imperata cylindrica & 1.99 & 1.99 & 1.99 \\
\hline 11 & Polygonum flaccidum & Polygonum flaccidum & 29.9 & 29.9 & 29.9 \\
\hline 12 & Artemisia carvifolia & Artemisia carvifolia & 5.23 & 5.23 & 5.23 \\
\hline 13 & Solanum nigrum & Solanum nigrum & 16.52 & 16.52 & 16.52 \\
\hline 14 & Clerodendrum cyrtophyllum & Clerodendrum cyrtophyllum & 24.5 & 24.5 & 24.5 \\
\hline 15 & Phytolacca acinosa & Phytolacca acinosa & 293.64 & 293.64 & 293.64 \\
\hline 16 & Eclipta prostrata & Eclipta prostrata & 11.05 & 11.05 & 11.05 \\
\hline 17 & Rhus chinensis & Rhus chinensis & 159.1 & 159.1 & 159.1 \\
\hline 18 & Oenanthe javanica & Oenanthe javanica & 29.45 & 29.45 & 29.45 \\
\hline 19 & Broussonetia papyrifera & Broussonetia papyrifera & 1811.46 & 1811.46 & 1811.46 \\
\hline 20 & Kalimeris indica & Kalimeris indica & 45.3 & 45.3 & 45.3 \\
\hline 21 & Commelina communis & Commelina communis & 3.57 & 3.57 & 3.57 \\
\hline 22 & Plantago depressa & Plantago depressa & 6.87 & 6.87 & 6.87 \\
\hline 23 & Duchesnea indica & Duchesnea indica & 3.02 & 3.02 & 3.02 \\
\hline 24 & Avena fatua & Avena fatua & 8.93 & 8.93 & 8.93 \\
\hline 25 & Conyza bonariensis & Conyza bonariensis & 279.69 & 279.69 & 279.69 \\
\hline 26 & Vicia hirsuta & Vicia hirsuta & 11.02 & 11.02 & 11.02 \\
\hline 27 & Rosa multiflora & Rosa multiflora & 29.85 & 29.85 & 29.85 \\
\hline 28 & Eragrostis pilosa & Eragrostis pilosa & 1.18 & 1.18 & 1.18 \\
\hline 29 & Humulus scandens & Humulus scandens & 217.78 & 217.78 & 217.78 \\
\hline 30 & Clematis hexapetala & Clematis hexapetala & 92.3 & 92.3 & 92.3 \\
\hline 31 & Erigeron acer & Erigeron acer & 4.9 & 4.9 & 4.9 \\
\hline 32 & Xanthium sibiricum & Xanthium sibiricum & 58.02 & 58.02 & 58.02 \\
\hline 33 & Pleioblastus amarus & Pleioblastus amarus & 2.55 & 2.55 & 2.55 \\
\hline 34 & Vicia sepium & Vicia sepium & 49.7 & 49.7 & 49.7 \\
\hline 35 & Daucus carota & Daucus carota & 63.3 & 63.3 & 63.3 \\
\hline 36 & Artemisia argyi & Artemisia argyi & 36.21 & 36.21 & 36.21 \\
\hline 37 & Gelsemium elegans & Gelsemium elegans & 40.79 & 40.79 & 40.79 \\
\hline 38 & Artemisia selengensis & Artemisia selengensis & 24.73 & 24.73 & 24.73 \\
\hline 39 & Miscanthus sinensis & Miscanthus sinensis & 403.01 & 403.01 & 403.01 \\
\hline 40 & Rubus howii & Rubus howii & 98.24 & 98.24 & 98.24 \\
\hline 41 & 41 & Setaria viridis & Setaria viridis & 39.47 & 25.21 \\
\hline 42 & 42 & Erigeron annuus & Erigeron annuus & 98.91 & 145.62 \\
\hline 43 & 43 & Arthraxon hispidus & Arthraxon hispidus & 12.94 & 7.40 \\
\hline 44 & 44 & Clinopodium chinense & Clinopodium chinense & 10.79 & 3.36 \\
\hline 45 & 45 & Carex tristachya & Carex tristachya & 21.46 & 18.17 \\
\hline 46 & 46 & Agrostis matsumurae & Agrostis matsumurae & 26.04 & 18.02 \\
\hline 47 & 47 & Poa annua & Poa annua & 121.66 & 71.57 \\
\hline 48 & 48 & Oxalis corniculata & Oxalis corniculata & 31.35 & 24.62 \\
\hline 49 & 49 & Conyza canadensis & Conyza canadensis & 135.14 & 38.75 \\
\hline 50 & 50 & Juncus effusus & Juncus effusus & 92.42 & 82.71 \\
\hline
\end{tabular}




\begin{tabular}{llllll}
\hline Rank No & Plot I & Plot I & $C_{\mathrm{B}}$ & $C_{\mathrm{B}}$ & $C_{\mathrm{B}}$ \\
\hline 51 & 51 & Cynodon dactylon & Cynodon dactylon & 499.02 & 280.91 \\
Sum & Sum & & & 33498.7 & 5532.6 \\
Rank No & Rank No & Plot II & Plot II & $C_{\mathrm{B}}$ & $C_{\mathrm{U}}$ \\
1 & 1 & Pharbitis nil & Pharbitis nil & 6.40 & 0.75 \\
2 & 2 & Chenopodium ambrosioides & Chenopodium ambrosioides & 42.37 & 21.59 \\
3 & 3 & Solanum nigrum & Solanum nigrum & 12.42 & 16.49 \\
4 & 4 & Oenanthe javanica & Oenanthe javanica & 46.05 & 30.45 \\
5 & 5 & Vicia hirsuta & Vicia hirsuta & 8.37 & 1.32 \\
6 & 6 & Clerodendrum cyrtophyllum & Clerodendrum cyrtophyllum & 28.14 & 61.10 \\
7 & 7 & Duchesnea indica & Duchesnea indica & 4.71 & 1.89 \\
8 & 8 & Clematis hexapetala & Clematis hexapetala & 107.13 & 6.79 \\
9 & 9 & Phytolacca acinosa & Phytolacca acinosa & 745.54 & 1327.8 \\
10 & 10 & Artemisia argyi & Artemisia argyi & 15.16 & 19.38 \\
11 & 11 & Setaria viridis & Setaria viridis & 42.31 & 101.43 \\
12 & 12 & Poa annua annua & 78.80 & 83.01 \\
13 & 13 & Daucus carota & Daucus carota & 125.30 & 124.74 \\
14 & 14 & Conyza canadensis & Conyza canadensis & 142.09 & 236.29 \\
15 & 15 & Erigeron acer & 81.98 & 83.16 \\
Sum & Sum & & 1486.8 & 2116.2 \\
\hline
\end{tabular}

\section{Hosted file}

Figures 2.docx available at https://authorea.com/users/318789/articles/451853-thermodynamicanalysis-of-an-ecologically-restored-plant-community-process-and-diversity 